\title{
Microbial Diversity Responded to Application of Nitrification Inhibitor in Greenhouse Cucumber Soil for Three Years
}

\author{
Ling WANG ${ }^{1,2,3, a}$, Bo-Wen $\mathrm{LI}^{1,3, b^{*}}$, Meng-Chao LIU ${ }^{2, \mathrm{c}}$, Guo-Yin ZHANG ${ }^{2, \mathrm{~d}}$, \\ Shi-You SUN ${ }^{2, e}$ and Ou-Ya ZHAO ${ }^{2, f}$
}

1. College of Resources and Environment Science, Agricultural University of Hebei, Baoding 071001 Hebei, China;

\section{Agricultural Resource and Environment Institute, Hebei Academy Agriculture and Forestry Sciences, Shijiazhuang 050051 Hebei, China;}

3. Key Laboratory for Farmland Eco-Environment of Hebei Province, Baoding, 071001 Hebei, China)

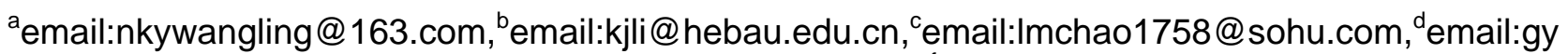
zhang1984@126.com, ${ }^{,} e m a i l: s u n s h i y o u @ 126 . c o m,{ }^{\dagger}$ email:zhaoouya1988@126.com.

\section{${ }^{*}$ Corresponding author}

Keywords: Cucumber; Rhizosphere microbiome; Nitrification inhibitor; Greenhouse; Microbial ecology

\begin{abstract}
Purpose] The Nitrification inhibitor plays a significant role in mitigation of climate change, leaching of nitrate nitrogen and improvement of agricultural productivity and quality in greenhouses. Here we show a strong correlation between soil microbes and cucumber root systems according to our observation in greenhouse in north China by application of nitrification inhibitor to cucumber soil. [Methods] The effects of environmental factors and the function of dominant flora were further explored by deep pyrosequencing of $16 \mathrm{~S}$ rRNA. [Results] It was shown that Proteobacteria, Actinobacteria, Chloroflexi, Germmatimonadates, Acidobacteria and Nitrospirae were the most abundant bacteria among all 783942 bacterial 16S rRNA genes clustering at the 97\% similarity level. Furthermore, the Chao1,Shannon and Simpson index of AOA diversity, as well as the ACE and Chao1 index of AOB diversity with In-1 and In-2 treatment was not significantly different with treatments FP. Reducing the use of chemical fertilizers and organic fertilizers by $25 \%$ (OPT) significantly reduces the microbial diversity in the soil. In addition, it was found $\mathrm{pH}$ and Organic matter play dominant role in community structure among. [Conclusions] The application of nitrification inhibitors for three years did not cause negative effects on the microbial diversity in soil, and it still maintained the richness and evenness of the diversity in greenhouse soil. This work provides deeper understanding for evaluation of managing nitrogen conversion process and its effect on environment in greenhouse soil.
\end{abstract}

\section{Introduction}

Soil responds to global climate change by generating or consuming greenhouse gases $\left(\mathrm{CO}_{2}, \mathrm{CH}_{4}\right.$, $\mathrm{N}_{2} \mathrm{O}$ et al.), and it is also an important part of the ecosystem feedback process [1]. Microorganisms are the main drivers of the geochemical cycle, especially the carbon and nitrogen cycle; they play an important role in regulating soil microbial ecological system functions such as nutrient cycling, decomposition of organic matter, maintaining soil structure, Greenhouse gases emissions and purification of environmental pollutants [2]. Soil nitrification is the process of ammonia oxidation to nitrite nitrogen and then to nitrate nitrogen driven by microorganisms. It is an important intermediate process connecting biological nitrogen fixation and denitrification in nitrogen cycle, not only directly affects the soil nitrogen supply and plant uptake, and soil acidification caused by excessive nitrogen fertilizer, nitrate leaching, water pollution and greenhouse gas emissions and a series of ecological environment problems, but also constitutes the central part of the nitrogen cycle [3-5]. Gärdenäs [6]discoursed that from molecular to global scale, interactions of carbon and nitrogen in soil, summarizes the five aspects of content, both $\mathrm{N}$ controls on the soil emissions of greenhouse gases and impact of rhizosphere priming on $\mathrm{C}$ and $\mathrm{N}$ cycling were put in the important 
place. Di. et al.clarified that the ammonia oxidising bacteria (AOB) rather than archaea (AOA) that were responsible for ammonia oxidation in nitrogen rich grassland soils and application of nitrification inhibitor inhibited emissions of greenhouse gases[7-12]. Therefore, the response and feedback of soil microbes to climate anomalies have become a hot topic in the field of international global change and microbial ecology.

In recent years, with the rapid development of China's facility cultivation, vegetable planting became a pillar industry for farmers to increase their income. The nitrification process of the soil in the production system of the facility vegetable was also a hot topic [13-18]. It was reported that frequent irrigation, over fertilization and low utilization of fertilizers were very popular in the actual production management of facility cultivation [18]. The vegetables planting area accounted for 11. $4 \%$ of national crop planting however consumed $22 \%$ of fertilizer in China [17]. The cultivation of facilities which changed the ecological environment of the soil was greatly different from that of food crops and the cultivation of crops in the open field. Nitrification inhibitors had a good effect on reducing greenhouse gas emissions and nitrogen leaching [3, 8-13]. Our research group found in previous research work, the nitrification inhibitors used in conjunction with organic fertilizer and chemical fertilizer, not only could reduce the negative impact of agricultural production to the environment, but also could improve production of crops in green house. Therefore, this research took cucumber in green house for an example, nitrification inhibitors were applied to for three consecutive years to explore the soil microbial response, adaptation and feedback mechanism, so as to provide important theoretical basis of soil microorganisms playing a crucial role on cutting the influence in agricultural activities on the climate change and the agricultural non-point source pollution.

\section{Materials and Methods}

\section{The Basic Properties of Study District}

The field experiment of interaction between cucumber root system and soil microbe in greenhouse was carried out with the soil treated by nitrification inhibitors from February 2015 to June 2017. The site of experiment located at the west of Shijiazhuang $\left(38^{\circ} 07^{\prime} 44^{\prime \prime} \sim 38^{\circ} 07^{\prime} 28^{\prime \prime} \mathrm{N}\right.$, $114^{\circ} 22^{\prime} 47^{\prime \prime} \sim 114^{\circ} 23^{\prime} 07^{\prime \prime} \mathrm{E}$ ) in Hebei province, which was the typical calcareous brown soil in northern China, and it was in the National Agricultural Environmental Science Investigation Station. The mean annual maximum and minimum temperatures in the area respectively varied between $35{ }^{\circ} \mathrm{C}$ and $-4{ }^{\circ} \mathrm{C}$, with an annual rainfall of $550 \mathrm{~mm}$ and 65 meters above sea level, which was a temperate continental monsoon climate. The basic properties of the soils were shown in Table 1.

Table 1 The Soil characteristics of plough layer $(0-20 \mathrm{~cm})$ in the study

\begin{tabular}{lccccccccc}
\hline $\begin{array}{c}\text { Organic } \\
\text { matter } \\
\left(\mathrm{g} \mathrm{kg}^{-1}\right)\end{array}$ & $\begin{array}{c}\text { Soil } \\
\mathrm{pH}\end{array}$ & $\begin{array}{c}\text { Total } \\
\mathrm{N}(\mathrm{g} \\
\left.\mathrm{kg}^{-1}\right)\end{array}$ & $\begin{array}{c}\text { Total } \\
\mathrm{P}(\mathrm{g} \\
\left.\mathrm{kg}^{-1}\right)\end{array}$ & $\begin{array}{c}\text { Total } \\
\mathrm{K}(\mathrm{g} \\
\left.\mathrm{kg}^{-1}\right)\end{array}$ & $\begin{array}{c}\text { Ammonia-N } \\
\left(\mathrm{mg} \mathrm{kg}^{-1}\right)\end{array}$ & $\begin{array}{c}\text { Nitrate-N } \\
\left(\mathrm{mg} \mathrm{kg}^{-1}\right)\end{array}$ & $\begin{array}{c}\text { Available Available } \\
\mathrm{P}\left(\mathrm{mg} \mathrm{kg}^{-1}\right)\end{array} \mathrm{K}^{\left(\mathrm{mg} \mathrm{kg}^{-1}\right)}$ \\
\hline Concentration & 14.32 & 8.2 & 1.14 & 0.82 & 19.19 & 1.01 & 60.2 & 28.37 & 73.50 \\
\hline
\end{tabular}

\section{Materials}

The cucumber varieties for experiment were Jinyou 1, which was produced by Tianjin Cucumber Research Institute. Nitrification inhibitor 1 was dicyandiamide (DCD), inhibitor 2 was 2-chloro-6-trichloromethyl pyridine. The chemical fertilizer were urea (N:46\%),Monoammonium phosphate (N:12\%; P:27\%), Potassium chloride(K:60\%). 40\% of chemical fertilizers were applied as the base and the other $60 \%$ were topdressing respectively on average during the flowering and fruiting stage of cucumber. The organic fertilizer (Total N 1.74\%; Total P 1.86\%; Total K 1.49\%; $\mathrm{pH}$ 8.14; EC $2.76 \mathrm{~S} / \mathrm{m}$ ) was all applied as the base. Fertigation was applied to the greenhouse cucumber plantation, with every $7 \sim 10$ day's frequencies to keep about $60 \%$ field moisture capacity. 


\section{Experimental Treatment}

The treatments included five applying fertilizer methods: No fertilizer to apply (CK), Farmers traditional application of fertilizer (FT), Farmers traditional application of fertilizer + Nitrification inhibitor 1(In-1), Farmers traditional application of fertilizer+ Nitrification inhibitor 2(In-2), 75\% of Farmers traditional application of fertilizer (Opt). Each treatment was set 3 repeats with $2.5 \mathrm{~m} 2$; there were 15 units in total. Between the units was separated by polyethylene plate with each other. 16 cucumber seedlings were planted in each unit. The different treatments in details of the experiment were displayed in Tab.2.

Table 2 The different treatments in the experiment

\begin{tabular}{|c|c|c|c|c|c|c|}
\hline \multirow{2}{*}{ Treatment } & \multicolumn{3}{|c|}{ Amount of Fertilization $\left(\mathrm{kg} \mathrm{hm}^{-2}\right)$} & \multirow{2}{*}{$\begin{array}{c}\text { Organic } \\
\text { matter } \\
\left(\mathrm{kg} \mathrm{hm}^{-2}\right)\end{array}$} & \multirow{2}{*}{$\begin{array}{c}\text { DCD } \\
\left(\mathrm{kg} \mathrm{hm}^{-2}\right)\end{array}$} & \multirow{2}{*}{$\begin{array}{l}\text { Pyridine } \\
\left(\mathbf{m L ~ h m ^ { - 2 }}\right)\end{array}$} \\
\hline & $\mathrm{N}$ & $\mathrm{P}_{2} \mathrm{O}_{5}$ & $\mathrm{~K}_{2} \mathrm{O}$ & & & \\
\hline CK & 0 & 0 & 0 & 0 & / & / \\
\hline $\mathrm{FP}$ & 750 & 180 & 525 & 6000 & / & / \\
\hline NIn-1 & 750 & 180 & 525 & 6000 & 22.5 & l \\
\hline NIn-2 & 750 & 180 & 525 & 6000 & / & 400 \\
\hline Opt & 563 & 135 & 394 & 4500 & l & / \\
\hline
\end{tabular}

\section{Soil Sampling and Analysis}

$2 \mathrm{Kg}$ soil [19] and rhizosphere soil [20] for analysis were collected from each treatment in June 2017 after the third stubble cucumber harvest. The soil environmental factors included ammonia-N, nitrate-N, organic matter, $\mathrm{pH}$. Extraction of soil ammonium and nitrate nitrogen were performed as follows: a sample of soil $(5 \pm 0.05 \mathrm{~g})$ was weighted into a $50 \mathrm{~mL}$ centrifuge tube and combined with $25 \mathrm{~mL}$ of $2 \mathrm{M}$ potassium chloride $(\mathrm{KCl})$ solution, The supernatant was filtered through 110 mmediameter filter paper into $30 \mathrm{~mL}$ vials and analyzed by a flow injection analyses FIA SFA CFA (Auto Analyzer 3-AA3,SEAL Company, Germany).Soil organic matter was determined by the method of potassium dichromate $\left(\mathrm{K}_{2} \mathrm{Cr}_{2} \mathrm{O}_{7}\right)$ oxidation - titration method in oil bath heating. Soil $\mathrm{pH}$ was determined by the potentiometric method with saturated calomel electrode [19]. Amplification and pyro sequencing of bacterial $16 \mathrm{~S}$ rRNA Genes in microbial community was analyzed with Illumina MiSeq platform.

The primer information of bacteria 16SrRNA was 338F (5'-ACTCCTACGGGAGGCAGCAG-3') and 806R (its sequence: 5'-GGACTACHVGGGTWTCTAAT-3') [21].

The primer information of Arch-amoA26F: 5'-GACTACATMTTCTAYACWGAYTGGGC-3'(26), and Arch-amoA417R: 5'-GGKGTCATRTATGGWGGYAAYGTTGG-3'(26) [22].

The primer information of amoB-1Fmod: 5'-CTGGGGTTTCTACTGGTGGTC-3'(21), and GenAOBR: 5'-GCAGTGATCATCCAGTTGCG-3'(20) [23].

\section{Statistical Analysis}

The mean and standard deviation were calculated using EXCEL 2007 (Microsoft, Redmond, WA, USA). Analysis of variance (ANOVA) among the different treatments was performed using SPSS 19.0 (SPSS, Chicago, IL, USA). The figure on the in soil was plotted using Origin 7.0 (Origin Lab Corp., Northampton, MA, USA). Alpha diversity analysis and taxonomic analysis used QIIME software. Metastats[24] analysis application was Mothur software, call Metastats (http://metastats.cbcb.umd.edu) the statistical algorithm. RDA redundancy analysis is a kind of typical constraint sorting method, was through the multiple linear regression(MLR) to flora structure data and the influence factors of a given fitting each other, and judging by displacement test, whether the factors impact on community structure significantly. The prediction of the metabolic function of bacteria and archaea was achieved by comparing the data of the existing 16srRNA gene sequencing data with the known microbial reference genome database of the 
metabolic function with PICRUSt tool (Phylogenetic Investigation of Communities by Reconstruction of Unobserved States, developed by Curtis Huttenhowen research group of Harvard University in the USA).In the prediction process, considering the difference of gene copy number of different species of $16 \mathrm{srRNA}$, the species abundance data in the original data was calibrated to make the prediction results more accurate and reliable[25].

\section{Results}

\section{The Screening of Key Spices}

The Difference of Microbial Diversity in Spices

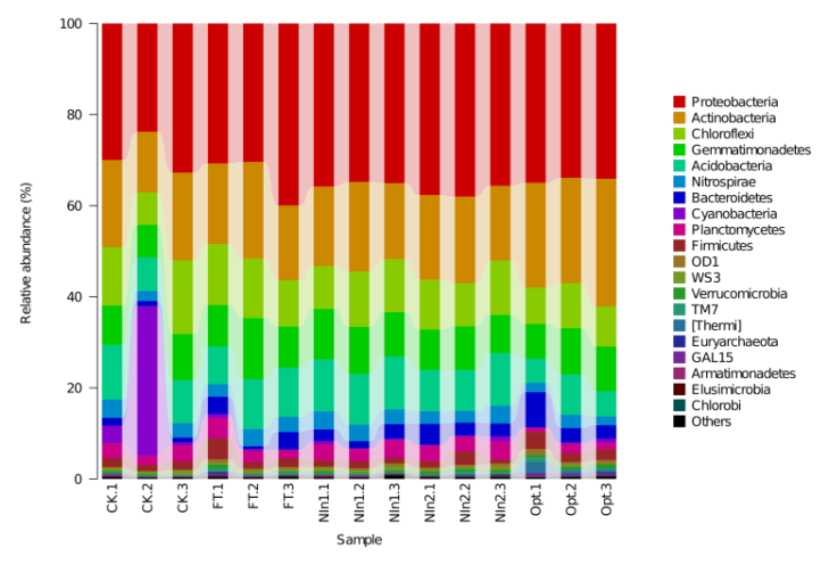

Fig. 1 Taxonomic composition and distribution of micro flora

After three years, the interaction between cucumber root systems and soil microbes responded to the application of nitrification inhibitor was further explored in greenhouse cucumber soil, according to the deep pyrosequencing of $16 \mathrm{~S}$ rRNA of rhizosphere microbial community, the results from Fig1. Dedicated that Proteobacteria, Actinobacteria, Chloroflexi, Germmatimonadates, Acidobacteria and Nitrospirae were the most abundant bacteria in total of 783942 bacterial 16S rRNA genes clustering at the $97 \%$ similarity level.

\section{The Difference of Microbial Diversity within Groups}

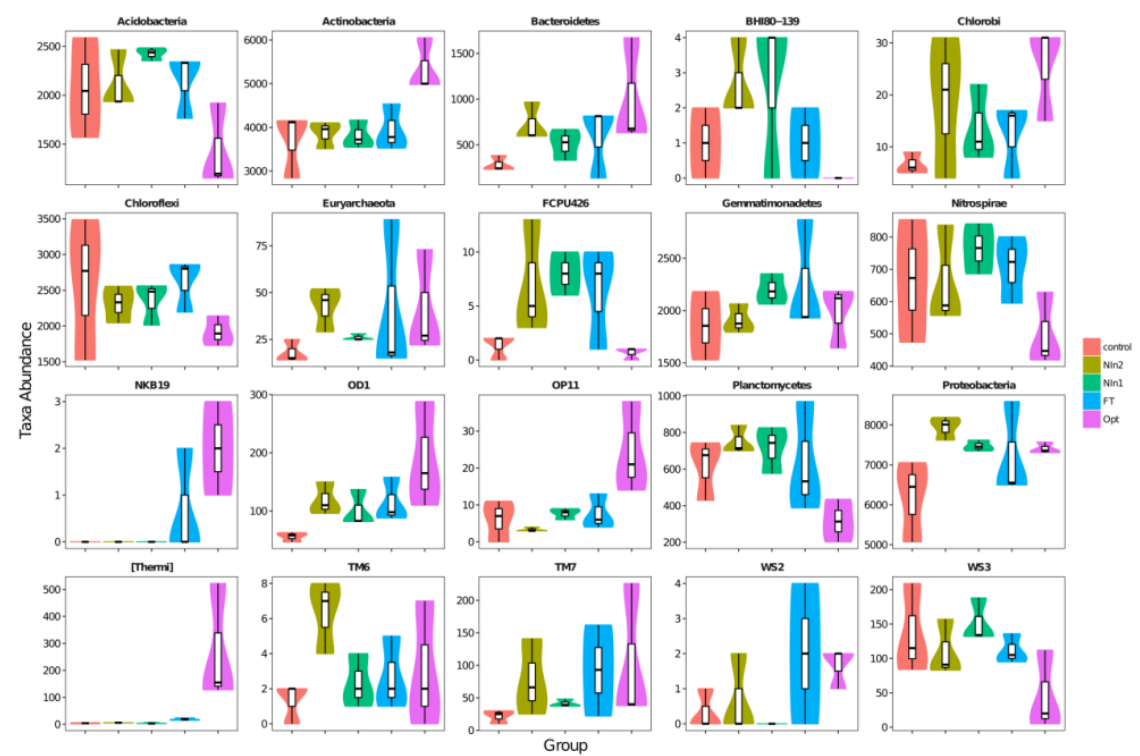

Fig. 2 The abundance of most different groups in top 20 OTU 
As we known, application of nitrification inhibitors could change the structure of microbial communities in greenhouse soils. The Fig.2 dedicated that there were significant differences in the top 20 OTU with different treatments. The most different species in top 3 with treatment In 1 were Acid bacteria, BH180-139 and Nitrospirae. The most different species in top 3 with treatment In2 group were TM6, FCPU426 and Chlorobi.

\section{Response of Soil Microbial Diversity to Nitrification Inhibitor Treatments}

\section{The Alpha Index of Diversity in v3v4 Micro Floras}

Table 3 The Alpha index of microbial diversity in V3V4 micro floras

\begin{tabular}{ccccc}
\hline Treatment & Chao1 & ACE & Shannon & Simpson \\
\hline CK & $2972.88 \pm 102.49 \mathrm{a}$ & $2988.75 \pm 107.58 \mathrm{a}$ & $9.21 \pm 0.46 \mathrm{a}$ & $0.963 \pm 0.02 \mathrm{a}$ \\
FP & $3478.87 \pm 96.71 \mathrm{a}$ & $3553.87 \pm 96.05 \mathrm{a}$ & $10.27 \pm 0.07 \mathrm{a}$ & $0.998 \pm 0.00 \mathrm{a}$ \\
OPT & $3035.12 \pm 129.85 \mathrm{a}$ & $3048.48 \pm 112.04 \mathrm{a}$ & $10.03 \pm 0.02 \mathrm{a}$ & $0.998 \pm 0.00 \mathrm{a}$ \\
In-1 & $3246.54 \pm 228.87 \mathrm{a}$ & $3353.40 \pm 268.22 \mathrm{a}$ & $10.24 \pm 0.05 \mathrm{a}$ & $0.998 \pm 0.00 \mathrm{a}$ \\
In-2 & $3178.31 \pm 188.41 \mathrm{a}$ & $3291.79 \pm 167.72 \mathrm{a}$ & $10.22 \pm 0.08 \mathrm{a}$ & $0.998 \pm 0.00 \mathrm{a}$ \\
\hline
\end{tabular}

In general, the Alpha index of diversity showed that the larger the index of Chao1 [26], ACE [27], the higher the richness of the community. The Shannon [28-29] and Simpson [30] index combined the richness and uniformity of microbial communities. The higher the index was, the higher the diversity of the community. While the Shannon index was more sensitive to community richness and rare OTU, and the Simpson index was more sensitive to uniformity and dominant OTU in the community.

It was showed by the Tab3. That each Alpha index of diversity with the CK treatment (no fertilizer) was all lower than the other treatments with using fertilizer. Although there was no significant difference in the diversity index with treatments FP, OPT,In-1, and In-2, the Chao1,ACE,Shannon index of diversity with FP and In-1 treatments were higher than the other treatments.

\section{The Alpha Diversity about AOA (Ammonia Oxidizing Archaea)}
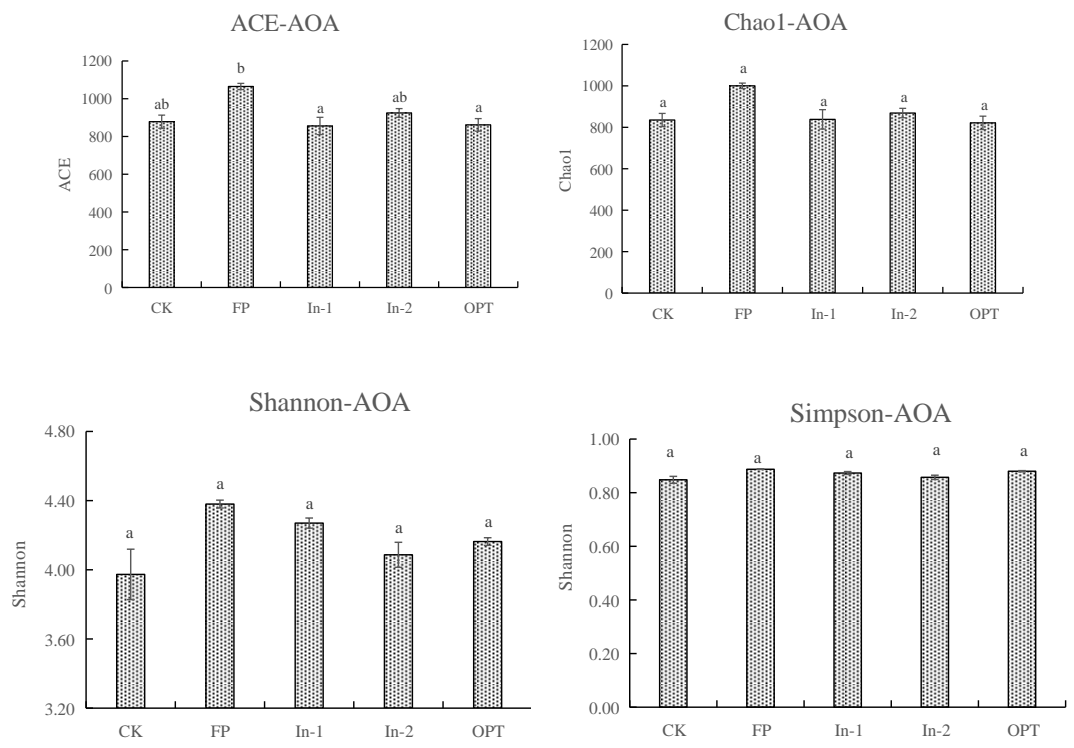

Fig. 3-6 The Alpha index of microbial diversity about AOA with different treatments

From Fig.3-6, the results dedicated that each Alpha index of diversity with the CK treatment (no fertilizer) was all lower than the other treatments. The ACE index of diversity about AOA with FP 
treatment was significant higher with treatments OPT, In-1, and In-2, the treatment In-1 was lowest. Although the Chao1, Shannon, Simpson index of diversity about AOA with all treatments were not significant different, the Chao1, Shannon index of diversity with FP treatment was higher than the others. The results illustrated that the richness of AOA was inhibited by In-1. The uniformity of dominant OTU in AOA was inhibited by In-2.

The Alpha Index of Diversity about AOB (Ammonia Oxidizing Bacteria)
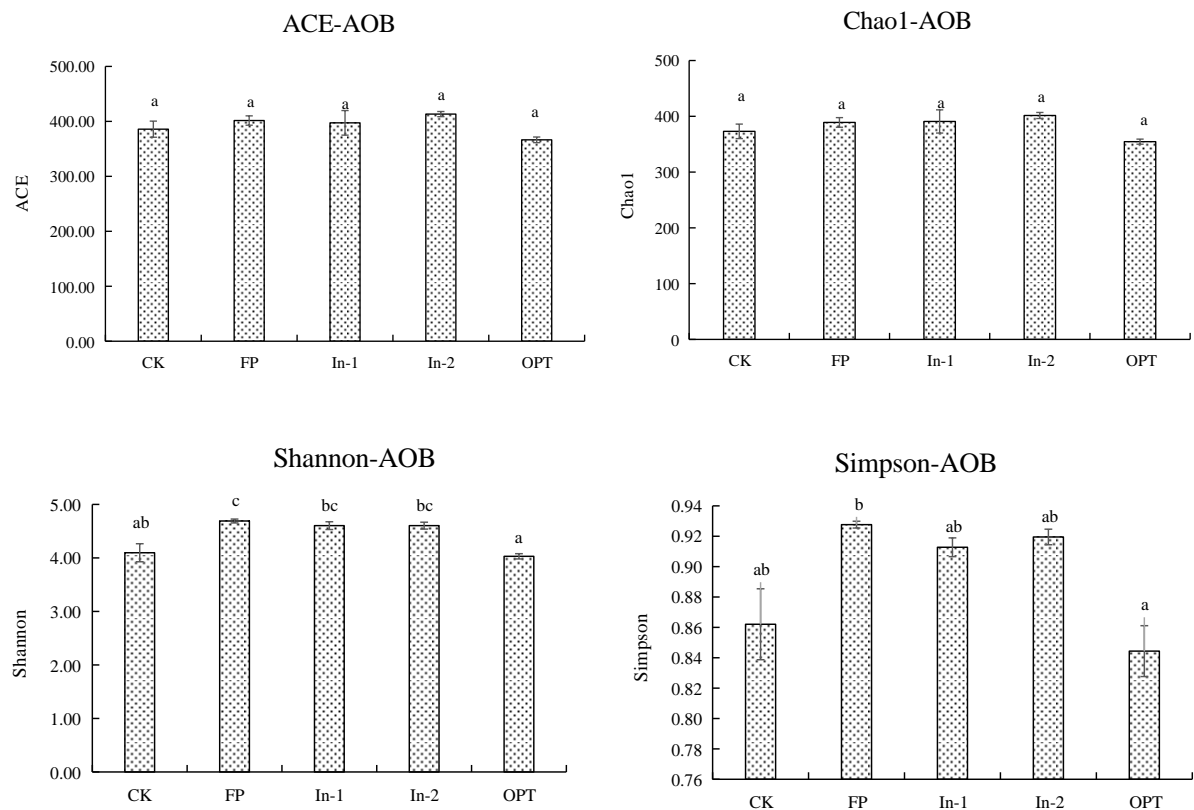

Fig. 7-10 The Alpha index of microbial diversity about AOB with different treatments

From Fig.7-10, the results made clear the ACE and Chao1 index of diversity about AOB with all treatments were not significant different. But Shannon and Simpson index of diversity about AOB with the treatment FP was higher than treatments OPT, In-1, and In-2, the treatment OPT was lowest, and there was no significant difference between the treatmentIn-1, and In-2. The results illustrated that the richness of rare OTU and the uniformity of dominant OTU in AOB were all inhibited by the application of nitrification inhibitor and fertilizer reduction. Reducing the use of chemical fertilizers and organic fertilizers by $25 \%$ (OPT) significantly reduces the microbial diversity in the soil.

\section{Relationship between Flora Structure and Environmental Factors}

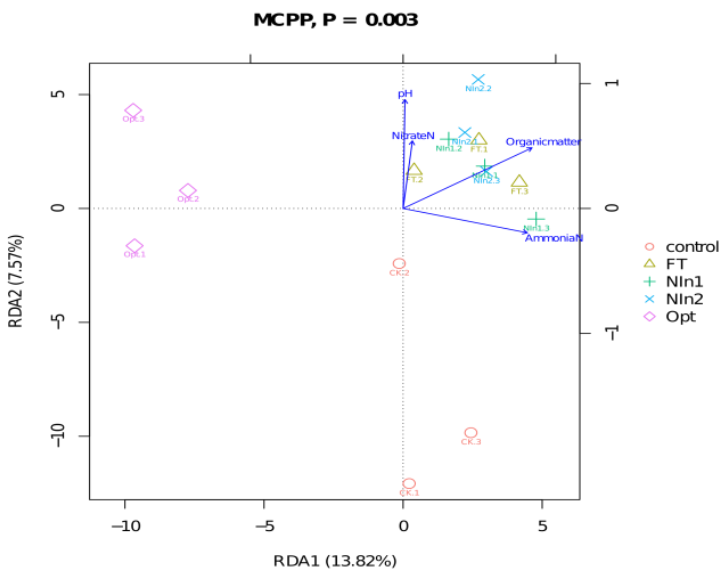

Fig. 11 The relationship between flora structure and environmental factors 
The relationship between flora structure and environmental factors was determined by RDA redundancy analysis. From Fig 11, the result showed that the similarity of community structure with FP, in-1 and in-2 was relatively high, while the treatment of CK and OPT was lower than that of other treatment groups. Furthermore there was a significant correlation between flora structures with different treatments group and the environmental factors. $\mathrm{pH}$ and Organic matter where are the most influential factors in community structure among the four factors. As the most important factor, $\mathrm{pH}$ was positively correlated with the organic matter and nitrate nitrogen, but was negatively correlated with the ammonium nitrogen. Organic matter was positively correlated with three other factors. The $\mathrm{P}$ value above the figure was obtained by Monte Carlo testing, and the smaller it was, the stronger the influence factors were on the community structure.

\section{Conclusion and Discussion}

According to the diversity of rhizosphere microbial community responded to the application of nitrification inhibitor in greenhouse cucumber soil in north of China, the interaction between cucumber root system and soil microbe for three years, the results dedicated that Proteobacteria, Actinobacteria, Chloroflexi, Germmatimonadates, Acidobacteria and Nitrospirae were the most abundant bacterial in total of 783942 bacterial $16 \mathrm{~S}$ rRNA genes after basic quality control. There were richer besides Di. et al. reported Nitrosopira were the dominant AOB species in high-N status grassland soils [7].Secondly, the Chao1, Shannon and Simpson index of AOA diversity, as well as the ACE and Chao1 index of AOB diversity with In-1 and In-2 treatment was not significantly different with treatments FP. Reducing the use of chemical fertilizers and organic fertilizers by $25 \%$ (OPT) significantly reduces the microbial diversity in the soil. $\mathrm{pH}$ and Organic matter where are the most influential factors in community structure among the four factors. To summary, The application of nitrification inhibitors for three years did not cause negative effects on the microbial diversity in soil, and it still maintained the richness and evenness of the diversity in greenhouse soil. This work provides deeper understanding for evaluation of managing nitrogen conversion process and its effect on environment in greenhouse soil.

\section{Acknowledgments}

The funding programs supported by National Key Technology R\&D Program in China (2015BAD23B01), China Scholarship Council (201408130101), and Key R\&D Project in Hebei (18223613D).We are very grateful to Shanghai Personal Biotechnology Co., Ltd for deep 16S rRNA pyrosequencing.

\section{Reference}

[1] SHEN Jupei,HE Jizheng. Responses of microbes-mediated carbon and nitrogen cycles to global climate Change, Acta Ecologica Sinica, 2011, 31(11):2957-2967.

[2] Singh B K, Bardgett R D, Smith P, Reay D S. Microorganisms and climate change: terrestrial feedbacks and mitigation options. Nature Reviews Microbiology, 2010, 8(11): 779-790.

[3] Arneth A, Niinemets U. Induced BVOCs: how to bug our models? Trends in Plant Science, 2010, 15(3): 118-125.

[4] He Jizheng, Zhang Limei. (2009).Advances in ammonia oxidizing microorganism and global nitrogen cycle.ACTA ECOLOGICA SINICA, 29(1):406-415.

[5] He Jizheng, Zhang Limei. (2013). Key processes and microbial mechanisms of soil nitrogen transformation.Microbiology China, 40:98-108.

[6] Gärdenäs A I, Ågren G I, Bird J A, Clarholm M, Hallin S, Ineson P, Kätterer T, Khicker H, Nilsson I, Näsholm T, Ogle S, Paustian K, Persson T, Stendahl J. Knowledge gaps in soil carbon 
and nitrogen interactions-From molecular to global scale. Soil Biology and Biochemistry, 2011, 43(4): 702-717.

[7] Di, H.J., Cameron, K.C., Shen, J.P., Winefield, C.S., O’Callaghan, M., Bowatte, S. and He, J.Z. (2009). Nitrification driven by bacteria and not archaea in nitrogen rich grassland soils. Nature Geoscience 2: 621-624.

[8] Di, H.J. and Cameron, K.C. (2011). Inhibition of ammonium oxidation by a liquid formulation of 3, 4-Dimethylpyrazole phosphate (DMPP) compared with a dicyandiamide (DCD) solution in six New Zealand grazed grassland soils. Journal of Soils and Sediments 11: 1032-1039.

[9] Di, H.J., Cameron, K.C., Shen, J.P., Winefield, C.S., O’Callaghan, M., Bowatte, S. and He, J.Z. (2011). Methanotroph abundance not affected by applications of animal urine and a nitrification inhibitor, dicyandiamide, in six grazed grassland soils. Journal of Soils and Sediments. 11: 432-439.

[10] Di, H.J. and Cameron, K.C. (2012). How does the application of different nitrification inhibitors affect nitrous oxide emissions and nitrate leaching from cow urine in grazed pastures? Soil Use and Management 28: 54-61.

[11] Di, H.J. and Cameron, K.C., Podolyan A, Robinson A.(2014). Effect of soil moisture status and a nitrification inhibitor, dicyandiamide , on ammonia oxidizer and denitrifier growth and nitrous oxide emissions in a grassland soil. Soil Biology and Biochemistry 73:59-68.

[12] Chaoyu Li, Hong J.,Di., Keith C.,Cameron, Andriy,Podolyan, Baocheng Zhu(2016). Effect of different land use and land use change on ammonia oxidizer abundance and $\mathrm{N}_{2} \mathrm{O}$ emissions, Soil Biology and Biochemistry 96:169-175.

[13] Nie Wenjing,Li Bowen, Guo Yanjie, Wang Xiaomin, Han Xiaoli.(2012). Effects of nitrogen fertilizer and DCD application on ammonia volitilzation and nitrous oxide emission from soil with cucumber growing in greenhouse. ACTA SCIENTIAE CIRCUMSTAINTIAE.32(10):2500-2504.

Hu-xiaoxia, Ding Hong, Zhang Yushu, Qin Shengjin, Li Shiqing.(2009).Nitrification denitrification potential different type in soils growth with vegetables. Journal Agro-Environment Science.28:2657-2662.

[14] Guo Yanqin,Gao Zhiliang,Zhang Ling,Qin Yanmei,Liu Shuwei,Zou Jianwen.(2010).Nitrogen of mineralization and nitrification in organic vegetable soils under greenhouse and open-air cultivation system. Journal Agro-Environment Science.29:2436-2442.

[15]Cui M,Sun X,Hu C,Di HJ,Tan Q, Zhao C.(2011). Effective mitigation of ni trate leaching and nitrous oxide emissions in intensive vegetable production syste ms using a nitrification inhibitor,dicyandiamide. Journal of Soils and Sediments 11:722-730.

[16] Guo Y., Li B.,Di H., Zhang L.,Gao Z.(2012).Effects of dicyandiamide(DCD) on nitrate leaching,gaseous emissions of ammonia and nitrous oxide in a greenhouse veg etable production system in northern China.Soil Science and Plant Nutrition 58:647-658.

[17] Yin Guanyi, Hu Kelin, Li pinfang, Liu Ronghao.(2013).Nitrogen Loss and Use Efficiency in Greenhouse Vegetable Soil Under Different Water and Fertilizer Managements. Journal Agro-Environment Science, 32:2403-2412.

[18] Chen qing. (2007).Theory and practice of comprehensive management of vegetable nutrient resources. China Agricultural University Press.

[19] Baoshi dan(2002).Soil and Agricultural Chemistry Analysis(The Third Edition).Beijing:China Agricultural University Press:25-90. 
[20] Derek S. Lundberg, Sarah L. Lebeis, Sur Herrera Paredes, Scott Yourstone, Jase Gehring, Stephanie Malfatti, Julien Tremblay, Anna Engelbrektson, Victor Kunin, Tijana Glavina delRio, Robert C.Edgar, ThiloEickhorst, RuthE.Ley, Philip Hugenholtz, Susannah Green Tringe \& Jeffery L. Dangl (2012). Defining the core Arabidopsis thaliana root microbiome. Nature, vol 488: 87-95.

[21] Xu, Nan;Tan, Guangcai;Wang, Hongyuan;Gai, Xiapu. Effect of biochar additions to soil on nitrogen leaching, microbial biomass and bacterial community structure. European Journal of Soil Biology 74(2016)1e8.

[22] Soo-Je Park, Byoung-Joon Park,Sung-Keun Rhee. Comparative analysis of archaeal 16S rRNA and amoAgenes to estimate the abundance and diversity of ammonia-oxidizing archaea in marine sediments.Extremophiles,July 2008, 12:605.

[23] Kelley A. Meinhardt, Anthony Bertagnolli, Manmeet W. Pannu, Stuart E. Strand, Sally L. Brown, David A. Stahl(2015).Evaluation of revised polymerase chain reaction primers for more inclusive quantification of ammonia-oxidizing archaea and bacteria.Environmental Microbiology Reports. Volume 7, Issue 2: 354-363.

[24]White, J.R.,Nagarajan, N., and Pop, M.(2009).Statistical Methods for Detecting Differentially Abundant Features in Clinical Metagenomic Samples. PloS Comput Biol 5.

[25]Langille ,M.G.I.,Zaneveld,J.,Caporaso,J.G.,McDonald,D.,Knights,D.,Reyes,J.A.,Clemente,J.C., BurKepile,D.E.,Thurber,R.L.V.Knight,R.et al(2013). Predictive functional profiling of microbial communities using 16S r RNA marker gene sequences. Nature Biotechnology 31:814.

[26] Chao,A.(1984).Nonparmetric Estimation of the Number of Classes in a Population. Scandinavian Journal of Statistics 11,265-270.

[27] Chao,A., and Yang, M.C.K.(1993).Stopping rules and estimation for recapture debugging with unequal failure rates.Biometrika 80,193-201.

[28] Shannon,C.E.(1948a). A mathematical theory of communication. The Bell System Technical Journal 27, 379-423.

[29]Shannon,C.E.(1948b). A mathematical theory of communication. The Bell System Technical Journal 27, 623-656.

[30]Simpson,E.H.(1949).Measurement of Diversity. Nature 163, 688. 